\title{
An exploratory qualitative study of values issues associated with training and practice in pluralistic counselling
}

Ellen Tilley, Julia McLeod and John McLeod

This is the peer reviewed version of the following article:

Tilley, E., McLeod, J. and McLeod, J. 2015. An exploratory qualitative study of values issues associated with training and practice in pluralistic counselling. Counselling and Psychotherapy Research. 15(3): pp. 180-187. doi: 10.1002/capr.12033

which has been published in final form at http://dx.doi.org/10.1002/ capr.12033. This article may be used for non-commercial purposes in accordance with Wiley Terms and Conditions for Self-Archiving." 
An exploratory qualitative study of values issues associated with training and practice in pluralistic counselling

Ellen Tilley (1)

Julia McLeod (1)

John McLeod (2)

(1) Division of Mental Health Nursing and Counselling, University of Abertay, Dundee DD1 $1 \mathrm{HG}$

(2) Department of Psychology, University of Oslo

\section{ABSTRACT}

Background: A pluralistic model of practice has become increasingly influential in recent years. A distinctive feature of this approach is its explicit grounding within a philosophical and moral perspective. Aim: The aim of the present study was to investigate issues and challenges that pluralistic counsellors experience in relation to values dilemmas that arise in practice. Methodology: Twelve practitioners, of various experience levels, who identified as pluralistic counsellors, were invited to take part in semi-structured interviews. Transcripts were analysed using a method of thematic analysis. Findings: Participants viewed their personal values to be compatible with the values that they perceived pluralistic counselling to hold, and reported that they chose pluralism as a modality because they found a similarity between their personal values and the values of pluralistic counselling. Core values associated with pluralistic practice included: the importance of connection, "there is no one 
right way to be", equality (not taking an expert role), honesty, and willingness to make use of research evidence. Participants also described values dilemmas, and their use of supervision in dealing with values issues. Implications: The implications of these findings for training, research and practice are discussed.

Keywords: counselling, values, pluralism, psychotherapy, qualitative, supervision, training, values

Several studies have found that values play a significant role in the process of counselling. Even if a therapist intends on remaining value-free, a client will pick up on the therapist's values (Kelly, 1990), typically resulting in values convergence (increasing similarity of client and therapist values over the course of therapy). Beutler, Jobe, \& Pollack (1978) found that client acceptance of the values conveyed by their therapist were linked to the development of trust. McLeod and McLeod (1993) observed a positive relationship between the extent to which person-centred practitioners espoused core humanistic values, and their effectiveness with clients. Patterson (1958) has argued that each theoretical model of counselling is associated with a distinctive set of values. Katz, Juni, \& Matz (2003) looked at a therapists undergoing psychoanalytic, training, and found that there was a consistency of values over the course of 14 years, suggesting that personal values that existed before entering training may continue to inform practice at later stages in a professional career (see also, Handelsman, Knapp, \& Gottlieb, 2005). There is also evidence that therapist awareness of values issues, and their competence in negotiating values differences, comprise central aspects of therapeutic effectiveness (Williams, \& Levitt, 2007) 
In their review of research into values and psychotherapy, Katz, Juni, \& Matz (2002) characterized the concept of values as an "elusive construct" that is hard to define. Traditionally, psychological research on values has relied on the use of questionnaire measures of abstract, discrete, universal attitude dimensions such as "equality', "freedom" and "justice" (Rokeach, 1973; Schwartz, 1994). However, Williams, \& Levitt (2007) have argued that, in respect of the goal of building knowledge that is relevant to the practice of counselling and psychotherapy, it is more useful to adopt a more contextualised approach that explores linkages between values domains, and reflects the values concepts and language actually used by practitioners. In addition, within the psychotherapy literature, there exists a tradition of understanding values as grounded within morality and ethics (Christopher, 1996; Cooper, 2009), and within political discourse (McLeod, 2013; Smail, 2005) in ways that are not readily transferrable into survey attitude questions. These considerations have resulted in a growing interest in the use of qualitative methodologies within the field of values research in counselling and psychotherapy, as a means of developing a more nuanced and contextualised understanding of this topic (Jennings, Sovereign, Bottorff, Mussell, \& Vye, 2005; Williams, \& Levitt, 2007).

The pluralistic framework for counselling and psychotherapy practice outlined by Cooper \& McLeod (2011) theoretically interesting area, in relation to the study of values, because it explicitly claims to reflect a moral position (pluralism). A pluralistic model of practice is based on an acceptance that there exist many possible answers, or change processes, that may be relevant to the resolution of the problems for which a client is seeking help. The process of pluralistic therapy involves collaboration between client and therapist around aligning the ideas and preferences of the client with the skills and knowledge of the therapist. Cooper \& McLeod (2011) have argued that this way of working is only possible if the therapist functions from a position of open-ness to dialogue, equality, and deep respect for 
the other. Within such an approach, a therapist also needs to be open to values differences, and willing to initiate conversation around these issues. Research into the role of values in pluralistic therapy is of special interest therefore, because it represents an area of practice in which values issues may be more salient than in other forms of therapy. It is also of interest to examine the extent to which the moral and ethical assumptions of the pluralistic model are reflected in the awareness of practitioners of this approach.

The aim of the present study was to contribute to an understanding of the values of counsellors who identified themselves as using a pluralistic model of therapy

\section{Method}

A semi-structured interview schedule was used that allowed participants to define values in their own way, and say anything that they felt as important. Interview transcripts were analysed using a descriptive approach that sought to stay as close as possible to the meanings expressed by participants.

\section{Participants}

As a small-scale exploratory study, the intention was to recruit participants that represented all stages of counsellor development from novice to expert. Recruitment took place within the professional communities linked to two counsellor training programmes in Dundee and Glasgow. Participants who were practising counsellors were contacted individually, based on a list provided by each organisation, with information about the study provided. The first 12 participants ( 7 female; 5 male) to reply were invited to take part, all of whom identified themselves as pluralistic counsellors. Levels of experiences ranged from recently-qualified, to 
more than 25 years post-qualification. Recruitment was closed once a sufficiently diverse sample was attained, in respect of gender mix and level of experience. Ethical approval for the study was granted by the Research Ethics Committee, School of Social and Health Sciences, University of Abertay Dundee.

Interviews

Semi-structured interviews were used to enable participants to reflect on their values as a pluralistic counsellor and to recall and describe one or two counselling episodes in which their own values did not match the values of their client, and a process of values negotiation took place. The interviews were designed to be broad and open-ended to allow the participants to share their own experiences. An interview schedule was created with prompts and follow up questions to engender meaningful and thoughtful answers (see Appendix A). To enable participants to appreciate the focus of the study, they were provided with a standard dictionary definition of values: "principles or standards of behaviour; and judgement of what is important in life." (OED, 2012). At the beginning of each interview, the interviewer briefly disclosed her background and interest in the topic, explained confidentiality procedures, and invited questions. Interviews took place on university premises and lasted between 45 and 80 minutes.

Data analysis

Interviews were carried out by the primary researcher (Ellen Tilley). Interviews were audio recorded and transcribed, and then analysed using thematic analysis (Braun and Clarke, 2006; Braun, Clarke, \& Rance, 2015), a technique for systematic qualitative data analysis that has 
been widely used in qualitative research in counselling and psychology, and was particularly appropriate for the present study in being flexibly oriented to the contextualised meanings used by participants within their everyday life settings. The validity of thematic codes identified by the primary researcher was audited by independent parallel analysis of segments of the data by two experienced qualitative researchers, who did not have access to information about the identity of participants. Portions of the data were also discussed in a research peer supervision group, under similar conditions of anonymity.

The researchers

The primary researcher (ET) was a postgraduate student in counselling at the time of the study, who had received training in the pluralistic approach. She has a background in gender studies, and an interest in cultural dimensions of therapy. Julia McLeod and John McLeod were co-supervisors of the study. Both are experienced qualitative researchers, who have been closely involved in the development of the pluralistic approach to counselling. The primary researcher kept a reflexive research journal, which formed the basis for discussions within the research team around the personal meaning of the study. All three members of the team believed, in advance, that values were an important factor in the choice to enter pluralistic training. However, they were not sure about the level of awareness of values that would be exhibited by research participants, or the pattern of values that might emerge.

\section{Results}

Analysis of interview material generated five main overarching values themes: the importance of connection, "there is no one right way to be", equality (not taking an expert 
role), honesty, and willingness to make use of research evidence (see Table 1). Participants also described values dilemmas, and their use of supervision in dealing with values issues. No meaningful differences were found between the values positions espoused by novice and expert counsellors within this sample.

\section{[insert Table 1 about here]}

The importance of connection

All participants identified the importance of connecting with their client as a central value within their work. This general theme consisted of three sub-themes: dialogue, respect, and collaboration. Typical participant statements were:

I really do believe that if you don't have relationship with client, a good foundation to work with, then it doesn't matter what you try and do. If you don't connect with the client they wont buy into the process.. (Participant 2)

I think another important value to pluralistic counselling is the importance of relationships and people being connected to each other. (Participant 1)

Several participants also highlighted a key subtheme, collaboration:

I think that there is something collaborative about it. That you and the client are on this process together trying to figure out what's gong on and what's going to be helpful. (Participant 12)

In addition, having respect for the client was a necessary aspect of a valued therapeutic relationship. It was clear that the participants felt that without respect for the client and the 
client's respect for the counsellor, then the relationship would not be well formed and the connection would not be there. In order to have a positive client/counsellor relationship the basic element of dialogue was essential:

I think dialogue is a pretty difficult thing to achieve. Which you know it is definitely a useful idea but uh in the end it's just like people talking to each other isn't it? But I think dialogue is a radical idea because most therapists do not open up to clients. (Participant 1)

Participants took the position that genuine connection could only be accomplished through dialogue that involved opening up to each other and being honest with each other.

"There is no one right way to be"

The participants of this study felt there are many right ways of being and that it is up to the individual to decide what it right for them at that moment in time:

I like any philosophy that says "what is it that is happening to you?" instead of trying to say how it should be... (Participant 6)

...just allowing people to have a point of view. In other words letting them feel they don't have to conform to what is expected of them necessarily. (Participant 9) 
A pluralistic approach was viewed as particularly consistent with this value position, because it advocates that it is necessary to work with each client to see what model fits for them. This includes valuing the client's personal freedom to choose what is right for them:

...I don't think its great to deny choices to your client... why should you deny them the choice to select the best, what they feel are the best parts, the best options for them in therapy. (Participant 2)

The ability to be open minded was highly valued and seen as part of accepting that there is not one right way of being. Participants believed that it was important to be open to both new ideas and old ideas:

I think pluralism provides a framework where we can have that openness. And not get stuck in our own kind of doctrine. (Participant 12)

I suppose the values of pluralism are like openness. Like curiosity. It is important value like...sort of a lack of certainness and openness to your way of seeing things.(Participant 1)

Being open and wanting to explore other ways of being was seen as an essential value to pluralism. To be able to hold these values participants felt a therapist also had to value creativity:

...I do value creativity very much and that is very essential to who I am and the way I like to look at things quite...almost like thinking out of the box more or less. Like 
let's see what your interpretations of the world are and lets see what you think and feel. I think that's working creatively. (Participant 10)

Equality (not taking an expert role)

Participants felt that in order to work pluralistically, a therapist needs to value equality between practitioner and client. This was seen as important because the participants believed that if one party had power over the other then there would not be a collaborative relationship.

I like things that are fair, you know, things that are fair...justice. Em yeah I have always had a strong sense of justice. (Participant 4)

....they are the expert on themselves and you know were only kind of facilitators in helping them along that journey...so its kind of like doing, you know, facilitating as best as possible; as it would be for them. (Participant 5)

This value seemed to be a high priority for all participants and essential to the way that they worked. When participants found that there was unequal power in a relationship with a client, they addressed and discussed with their clients in attempts to resolve the problem. For most participants the value conflict of power and equality was not one they were willing to compromise on, because they felt it was detrimental to the relationship they had with their client. Participants often struggled maintaining and equal relationship with their clients, but 
they found that by being flexible they were more likely to maintain and equal balance of power:

...being a pluralistic counsellor I found that you have to adapt to people and that some people might not want to set goals and some people like to set goals every day and other people just want to set a goal, you know...flexibility. (Participant 4)

Honesty

Participants believed that without honesty, and a willingness to be open with the client, no real therapy could take place. Honesty was not only seen as an attribute for the client to have with the therapist, but also for the therapist to have with the client.

And that same kind of genuine kind of congruence that... instead if just holding onto it and just thinking about it; put it there to the client. (Participant 5)

In addition honesty was discussed in terms with being honest with oneself, through a commitment to reflexivity:

Being true to yourself and reflecting on how things are going on personally for you... and how I truly think about things... (Participant 3)

Something I like about pluralism is the reflexivity of it. I think it makes me as a counsellor more reflective of my practice and work... critical of my practice in a good way so I can really critically reflect upon what I'm doing. It helps identify what my stuff is and what the client's stuff is and not get confused and mix stuff altogether. (Participant 5) 
Participants believed it was necessary to honestly reflect upon their practice and how it felt for them, but also to be able to check in with the client and the client's reflections. Participants described honesty within a therapeutic relationship as something that could be difficult to achieve. There were dilemmas around what to disclose to clients and how to disclose thoughts/experiences to clients.

Willingness to make use of research evidence

Participants highlighted the importance of research in relation to their practice. One participant talked about the way a research-informed approach to therapy built on values that he had acquired earlier in his career:

In terms of studying psychology ... at that time...you had to study philosophy as well.

I suppose what I got from that was that you had to really be able to argue the case that you believed in you had to be able to put forward evidence in what you believed in and you had to be prepared for that evidence to be challenged by other people. (Participant 1)

A few participants believed that practicing without a research base could be considered as unethical.

Further themes 
In addition the set of personal and professional value themes outlined above, participants in this study also discussed the factors that influenced their choice of pluralistic training, values dilemmas that they had encountered in their practice, the role of supervision in enabling them to resolve these dilemmas, and their experience of training.

All participants were able to describe ways in which the values of the pluralistic approach were consistent with political, philosophical and ethical choices that they had made at various stages in their lives. For example, one informant talked at length about how her previous carer as a social worker had given her an appreciation of the strengths of her clients, and the importance of adopting a flexible approach to helping. All of the participants reported that these personal experiences had been instrumental in the decision to enter pluralistic training.

The most widely-reported area of values conflict was associated with the intention of the therapist to adopt a non-expert role (equality):

And he felt like everyone else was around to fix his problems. So he would come into sessions and he would tell me what the problem is and expect me to throw suggestions at him. And he would hit them back with a bat and it was very much the case of I was working for him. And then it's not like that I would have liked to have the power I was just very uncomfortable with just one person having all the power in that relationship. (Participant 2)

To resolve values conflicts, participants reported that they would either give priority to their values and discuss the dilemma with their client, or give priority to the client's values because the value at conflict was not as highly held as the value for the client's right to hold his/her own values. The therapists who chose to discuss the conflict with their client believed that by doing so they could collaboratively decide on a solution that worked both parties. In addition 
they felt by bring forth the dilemma they were being congruent and creating open dialogue with the client.

Participants who did not bring forward a discussion about the value conflict with their client often used supervision as a way of resolving this tension. Participants also reported that they used supervision in general as a way to better understand their values and how to work with the client's values:

I found that group supervision has been really great for me to begin to understand my values... and how they are integrated into pluralistic counselling. I find it really interesting in a group environment because you have people there that challenge the decisions that you made. And it really makes you stop and think about, well was that the right decision? Why did I make that decision? Would I have made that same decision if that same situation happened again. (Participant 2)

Participants reported that, although they were aware of the moral and values stance of the pluralistic approach through reading, and particularly mentioned the relevant sections of the Cooper \& McLeod (2011) textbook. However, they reported that their training had not included any extended or experiential exploration of this topic. All participants described their interview as having been a meaningful and satisfying experience, which was personally useful in allowing them an opportunity to reflect on their practice and professional development.

\section{Discussion}


The findings of this study indicate that pluralistic counsellors are aware of their values, and report that these values guide them in their practice. It was evident that the participants viewed their personal values were compatible with the values that they perceived pluralistic counselling to hold. Participants chose pluralism as a modality because they found a similarity between their personal values and the values of pluralistic counselling. The values identified in the present study are not unique to the modality; they are all shared, to a greater or lesser extent, with other modalities. Further research, into practitioners trained in other orientations, would be required to determine the distinctiveness of the values position associated with pluralistic practice. The present study provides a start point in relation to further research on this topic.

It is necessary to interpret the findings of this study with caution. A key limitation of this study was the selection of the participants. Participants needed to be practicing pluralistic counselling. At the present time, there exists only a relatively small network of pluralistic counsellors, who tend to be known to each other. This factor may have affected participant willingness to disclose. For instance, participants may have felt awkward or perhaps judged if they were not sure of an answer. However, the interview schedule that was used appeared to have been effective in making it possible for participants to provide rich and varied accounts of their value positions.

One of the striking findings of the current study was the co-existence, in these pluralistic counsellors, of relational (connection) and scientific values, alongside a broadly socio-political commitment to power equality and a valuing of personal authenticity (honesty). This somewhat broad values profile appears to be different from the patterns of values expressed by practitioners who base their work in singular modalities. For example, 
Katz, Juni, \& Matz (2002) found that psychoanalytic therapists heavily identified with relational values, while Bilgrave \& Deluty (2002) found that cognitive-behavioural practitioners strongly affiliated with scientific values while humanistic therapists were more influenced by spiritual values. One of the possible implications of the present study, is that therapist values may vary on a dimension of complexity vs. simplicity. It would be useful, in further research, to explore the extent to which values complexity is advantageous to therapists, in allowing them to more readily identify areas of values concordance with their clients. Studies carried out by Jennings et al. (2005) and Williams and Levitt (2007) explored the values positions of expert or "master" therapists, and found that these practitioners could be characterised as operating on a basis of a capacity to hold apparently competing values positions at the same time, for example expertise and humility (Jennings et al., 2005).

The values discussed in this study have important implications for our understanding of the ways in which pluralistic therapists work with their clients. Traditionally, therapists have been advised that they should keep their personal values out of therapy (Patterson, 1958). By contrast, participants in this study reported that it was useful for them not only to reflect on how their values were influencing their practice, but also to discuss values conflicts with their clients, as a means of being respectful and collaborative and operating from a nonexpert stance. These findings, around how therapists respond to value conflicts, largely replicate the conclusions of Williams and Levitt (2007) around how expert therapists dealt with values conflicts by bringing them into the open and being willing to discuss them with their clients.

The findings of the present study have important implications for understanding therapist personal and professional development (Rønnestad, \& Skovholt, 2013). On the basis of the interviews that we conducted, it would appear a sufficient degree of concordance between pre-training personal values, and the values stance adopted by the training 
programme being entered, can make a positive contribution to trainee learning and development.

Participants in this study reported that they had a sense of working through value conflicts and interventions, in their interactions with clients without being fully aware that that was what they were doing. All of them stated that they found that the experience of being interviewed had helped them to reflect on their values, and that they wished that values issues had received more attention in their primary training. Useful perspectives on how therapists can understand their values and how to work with their values in practice can be found in Tjelveit and Gottlieb (2010) and Vachon and Agresti (1992).

As a preliminary study, one of the aims of this investigation was to identify potential areas for future research. Our experience was that the interview schedule used in the present study was broadly effective in enabling participants to articulate their values. In terms of analysing the data, our experience was that there were several informant statements that were not easy to interpret. One recommendation for future research in this area would be to carry out two interviews with each participant, so that areas of ambiguity could be clarified, or explained in more detail, at a second meeting. It may also be useful for further research to focus on specific value domains. For example, our impression was that the participants in our study used terms such as "honesty" and "dialogue", or the process of deciding what to disclose to clients, in ways that were somewhat different from the ways that these concepts are employed in other therapy traditions. In the context of an interview into the entire range of values espoused by a person, there is not sufficient space to explore specific domains in depth. In the present study, there was a surprisingly high level of concordance across informants, in relation to the main values which which they identified, probably because they were all drawn from a relatively small professional community. It would be helpful if further 
research could develop a more differentiated picture of pluralistic values, for example by including therapists from other approaches who have adopted the pluralistic framework later in their careers, or therapists who had rejected or moved away from a pluralistic approach. Finally, it is essential to appreciate that the present study only analysed therapist reflective accounts of their values. It is important that further research explores values-in-practice, for example by inviting therapists to listen to recordings of their work and talk about their moment-by-moment experience of being aware of value dilemmas and making choices around how to deal with them.

\section{References}

Beutler, L.E. Jobe, A., \& Pollack, S. (1978). “Acceptance,” values, and therapeutic change. Journal of Consulting and Clinical Psychology, 46, 198-199.

Bilgrave, D.P., \& Deluty, R.H. (2002). Religious beliefs and political ideologies as predictors of psychotherapeutic orientations of clinical and counseling psychologists. Psychotherapy: Theory, Research, Practice, Training, 39, 245-260.

Braun, V. and Clarke, V. (2006). Using thematic analysis in psychology. Qualitative Research in Psychology, 3, 77-101.

Braun, V., Clarke, V., \& Rance, N. (2015). How to use thematic analysis with interview data. In A. Vossler, \& N. Moller (eds) The counselling and psychotherapy research handbook. (pp. 183-197). London: Sage. 
Christopher, C.J. (1996). Counselling's inescapable moral visions. Journal of Counseling and Development, 75, 17-25.

Cooper, M. (2009). Welcoming the Other: Actualising the humanistic ethic at the core of counselling psychology practice. Counselling Psychology Review, 24, 119-129.

Cooper, M., \& McLeod, J. (2011). Pluralistic counselling and psychotherapy. London: Sage.

Handelsman, M.M. Gottlieb, M.C., \& Knapp, S. (2005). Training ethical psychologists: an acculturation model. Professional Psychology: Research and Practice, 36, 59-63.

Jennings, L., Sovereign, A., Bottorff, N., Mussell, M.P., \& Vye, C. (2005). Nine ethical values of master therapists. Journal of Mental Health Counseling, 27, 32-47.

Jensen, J.P., \& Bergin, A.E. (1988). Mental health values of professional therapists: A national interdisciplinary survey. Professional Psychology; Research and Practice, 19, 290297. 
Katz, B. Juni, S., \& Matz, P. (2002). The values if psychoanalytic psychotherapies at two points in time (1979 vs. 1993): A cross-over comparative study. Current Psychology: Developmental, Learning, Personality, Social, 21, 339-361.

Kelly, T.A. (1990). The roles of values in psychotherapy. Clinical Psychology Review, 10, $171-186$

McLeod, J., \& McLeod, J. (1993). The relationship between personal philosophy and effectiveness in counsellors. Counselling Psychology Quarterly, 6, 121-129.

McLeod, J. (2013) An introduction to counselling. $5^{\text {th }}$ edn. Maidenhead: Open University Press.

OED (2012). Oxford English Dictionary. London: Oxford University Press.

Patterson, C.H. (1958). The place of values in counselling and psychotherapy. Journal of Counseling Psychology, 5, 216-223.

Rokeach, M. (1973). The nature of human values. New York: Free Press.

Rønnestad, M. H., \& Skovholt, T. M. (2013). The developing practitioner: Growth and stagnation of therapists and counselors. New York: Routledge.

Schwartz, S.H. (1994). Are there universal aspects in the content and structure of values? 
Journal of Social Issues, 50, 19-45.

Smail, D. (2005). Power, interest and psychology. Ross-on-Wye: PCCS Books.

Tjelveit, A.C., \& Gottlieb, M.C. (2010). Avoiding the road to ethical disaster: overcoming vulnerabilities and developing resistance. Psychotherapy Theory, Research, Practice, Training, 47, 98-110.

Vachon, D.O., \& Agresti, A.A. (1992). A training proposal to help mental health professionals clarify and manage implicit values in the counseling process. Professional Psychology: Research and Practice, 23, 509-514.

Williams, D.C., \& Levitt, H.M. (2007). A qualitative investigation of eminent therapist's values within psychotherapy: developing integrative principles for moment-to-moment psychotherapy practice. Journal of Psychotherapy Integration, 17, 159-184. 
Appendix A Interview schedule: values of pluralistic counsellors

1. I am interested in the values that are important to you as a person and as a counsellor. To help us to begin to explore your values, it would be helpful if you could briefly take me through your life, from your childhood, and tell me about the beliefs and values that you were exposed to at different times, the experiences, people and groups that influenced you in this area, and the decisions that you made regarding the values positions that are now most important for you.

2. In what ways were your values involved in the decision to become a counsellor?

3. What drew you to the idea of pluralistic counselling, as a particular approach to therapy?

- In what ways/to what extent was research evidence influential in this decision?

4. What do you understand are the values of pluralistic counselling?

- Are some values more important than others? If yes how so?

5. Do you find these values to be unique to pluralism? If so why yes or no?

- Does pluralism have its own set of values or do you find that its values are not unique to pluralism, but are shared with other theoretical orientations?

- Do the values compare to any particular counselling modality? How so?

6. When working with clients have you had an experience where there was value conflict between you and the client? If possible, give a specific example.

- What happened? Were you able to resolve this conflict? How so?

- What might you have done differently? 
- What has this experience taught you anything about you own values as a counsellor?

- Is there another example of values conflict that you can describe?

7. Please take a moment to reflect upon your own personal values. How do you find your own personal values and the values of pluralistic counselling work together?

- Do they fit well together?

- Are there shared values?

- Can you tell me of an experience when you had value conflict between your own personal values and the values of pluralistic counselling?

- How did you resolve this?

- What did you find helpful?

- What wasn't helpful?

8. Are there any training experiences you have attended, or books/articles you have read, that have been particularly useful for you?

9. Is there anything else you would like to add? What was your experience of being interviewed? 
Table 1. Thematic analysis of pluralistic counsellor values

\begin{tabular}{|l|l|}
\hline Overarching theme & Subthemes \\
\hline The importance of connection & $\begin{array}{l}\text { Dialogue } \\
\text { Respect } \\
\text { Collaboration }\end{array}$ \\
\hline "There is no one right way to be" & $\begin{array}{l}\text { Valuing person freedom } \\
\text { Being open-minded } \\
\text { Creativity }\end{array}$ \\
\hline Equality (not taking an expert role) & $\begin{array}{l}\text { Sensitivity to power imbalance } \\
\text { Flexibility }\end{array}$ \\
\hline Honesty & $\begin{array}{l}\text { Being open with the client } \\
\text { Reflexivity }\end{array}$ \\
\hline $\begin{array}{l}\text { Willingness to make use of research } \\
\text { evidence }\end{array}$ & \\
\hline
\end{tabular}

